trained health workers will be able to spearhead new initiatives in the emergent health structures.

Health Unlimited,

G M C HOLDSWORTH

1 Godlee F. Médecins Sans Frontières comes to Britain. $B M \mathcal{Y}$ 1992;305:1382-3. (5 December.)

EDITOR,-In her report on Médecins Sans Frontières Fiona Godlee mentions its difficulties in recruiting doctors for emergency medical aid.' Many more doctors would volunteer to work in developing countries if this did not have a negative effect on their subsequent careers, particularly in hospital medicine. The benefits to the community in which this work is undertaken is beyond doubt; the benefit to the doctor's personal and professiona development is also considerable. ${ }^{2}$ Lord Owen is correct to emphasise the difficulties of "stepping off the ladder," but his call to health authorities for more flexibility is misdirected (unless he is using health authorities as a general term). The current working pattern of short term contracts for junior hospital doctors, for all its faults, allows time out easily.

The stage at which doctors who wish to combine work in a developing country with a hospital career are discriminated against is at job interviews, particuarly selection panels for senior registrar training. It is the medical profession that holds the remedy. Until experience in the Third World is seen to be at least as valuable as, for instance, research posts or experience in other developed countries doctors in training will not be able to volunteer without jeopardising their careers and we as a profession will obstruct valuable aid.

R J BALL

Department of Paediatrics,

District General Hospital,

Warrington WA5 IQG

1 Godlee F. Médecins Sans Frontières comes to Britain. $B M \mathcal{Y}$ 1992;305:1382-3. (5 December.)

2 Williams CJC. Advantages of working in the developing world dilliams CJC. Advantages of working in the developing
during paediatric training. Arch Dis Child 1992;67:330-2

\section{Health promotion in general practice}

EDITOR,-I am dismayed and angry that the General Medical Services Committee has caved in to the government over health promotion and its future. ${ }^{\prime}$ Yet again a group of self interested general practitioners who do not represent the majority have allowed the government to ride rough shod over agreements made less than three years ago to allow general practitioners to earn performance related pay. Because of some individuals abusing the system by introducing "noddy" clinics and others arguing against three yearly checks, and the government realising that performance related pay is an open ended agreement (what else can it be unless the performance itself is limited?), those of us who get on with improving performance and patient care and strive hard to make health promotion work for our patients and our practices find ourselves losing thousands of pounds. We are underrepresented on the negotiating committees not through lack of interest but through lack of opportunity, tending to work in small and singlehanded practices.

The winners will be those practices that previously never bothered to implement any sort of planned care on the scale required to be effective. They will now, simply by taking histories from patients, qualify for the ludicrous banding system, which allows a government in the pockets of the tobacco companies and other groups with vested interests to pay lip service to providing comprehensive preventive care to the nation. When, because of the ineffectiveness of the proposed new system, the nation remains "sick" general practitioners will be ideally placed to take the blame.

We asked for trial runs for the new contract and were denied them; we asked for trial runs of fundholding, which were again denied. This new system is also to be introduced without any trial run. As our negotiators come mainly (I presume at least $60 \%$, from the GMSC's vote) from well healed large practices and have plenty of time and money to sit on comfortable committees and negotiate away the rest of our livelihoods, it seems that the negotiating stance has been to protect the "fat cats" on committees at the expense of those doing the real work in the real world. All this comes at a time when we will soon be expected to pick up the pieces of an underfunded Community Care Act, we are already dealing with the health effects of mass unemployment, and doctors and our public sector colleagues are carrying the can for the government's economic mismanagement with an effective pay cut.

When is the profession going to stand up for itself? Where is the leadership of 1966? When are we going to say that enough is enough and threaten to resign en masse unless the NHS is protected from the maulings of a discredited, mealy mouthed, and dishonourable government? I ask all concerned to write to their local medical committee, GMSC representative, and MP. The negotiators have let us down. Grass roots opinion must now speak for itself.

DUNCAN M WILLIAMS

Meddygfa'r Waun,

Gwaun-Cae-Gurwen

Ammanford,

Dyfed

1 Beecham L. New health promotion package. BMF 1992;305: 369-70. (28 November.)

\section{Specialist training}

EdIToR,-We are sorry that Robert F Kehoe and the collegiate trainees committee of the Royal College of Psychiatrists cannot support the views of the Junior Doctors Committee and Hospital Doctors Association on specialist training.' It is clear from Kehoe's letter that the collegiate trainees committee is committed to organising the kind of structured training we would like to see implemented for all specialties.

We wish to answer specific points in Kehoe's letter. Though $8-10 \%$ of juniors may be in psychiatric posts and the collegiate trainees committee represents their training interests in relation to the college, it is the Junior Doctors Committee that represents all juniors in relation to national matters such as staffing structure and terms and conditions of service. Our proposals are intended to give a national framework to an overall reform of the postgraduate medical system. We have never contemplated dictating to any specialty what its training requirements should be.

In wishing to retain separate registrar and senior registrar grades rather than create a single specialist training grade the Royal College of Psychiatrists is alone among the major specialties. How representative the collegiate trainees committee is of its members with regard to their views on training is thus questionable, especially when a recent survey in Hospital Doctor found that $87 \%$ of psychiatrists (who were by far the largest group of specialists responding) were in favour of reform of training. ${ }^{23}$

The solution to the current difficulties supported by Kehoe has been recognised by the Department of Health as having major problems and has been found by an independent Queen's counsel to be almost certainly unlawful in a European context.

We hope that the collegiate trainees committee will continue to contribute to the debate and that it will take up the earlier invitation to meet with the
Junior Doctors Committee and other juniors' groups to discuss our joint futures.

A J CARNEY

C D H WREDE

Junior Doctors Committee,

BMA,

London WC1H 9JP

1 Kehoe RF. Specialist training. BMF 1992;305:1290. (21 November.)

2 Reed Healthcare Communications. Doctor and Hospital Doctor's open survey on medical education and training. Guildford: Reed Healthcare Communications, 1992.

3 Medical training flunks its test. Hospital Doctor 1992 Oct 15:34.

EDITOR,-I am concerned by the inaccurate accounts of the Junior Doctors Committee's proposals to resolve the problems of specialist training, certification, and staffing. ${ }^{2}$ The committee's submission to the chief medical officer's working group addresses the difficulties that have arisen from the United Kingdom's non-implementation of the European Community's medical directives ${ }^{3}$; it also addresses the problems of inefficient training, inadequate supervision, and poor planning of staffing, which have been brought into focus by other reports. ${ }^{4}$

The Junior Doctors Committee has called for a reduction in the duration of training, which must become more intensive and be better monitored. Immediately after full registration trainees should be able to enter specialist training programmes comprised of general and higher phases. Assessment should be provided regularly, with reduced reliance on examinations and greater emphasis on continuous open assessment. There should be sufficient flexibility for research and "outside" experience.

Certification of completion of specialist training which is legally equivalent to the certificates of other member states of the European Community, would be an end point that would satisfy the European Commission and answer public calls for greater accountability. Such certification would confer eligibility to apply for a consultant post and to engage in private practice. The Junior Doctors Committee remains committed to a single post career grade after certification, the consultant.

A dramatic increase in the number of consultants would be required to ensure reasonable career progression and to permit consultants to take on an increased role in training and supervision while maintaining their service commitments. The Junior Doctors Committee recognises the resource implications of consultant expansion and has identified means of containing these costs. Access to specialist services remains contentious; the committee remains committed to the "gatekeeper" role of the general practitioner.

Since an open invitation was extended to all specialty trainees' groups discussions between members of the committee and representatives of the specialties of anaesthetics, orthopaedics, pathology, radiology, surgery, and ear, nose, and throat surgery have led to an unprecedented consensus based on the principles outlined above. The committee welcomes further discussion of its proposals and will provide copies of its submission to ensure that this is based on fact.

Chairman,

EDWIN BORMAN

Junior

London WC1H 9JP

1 Kisely S. Specialist training. BMF 1992;305:1021. (24 October.)

2 Kehoe R. Specialist training. BMf 1992;305:1290. (21 November.)

3 Junior Doctors Committee. Submission to the chief medical officer's working group on specialist training, certification and manpower. London: BMA, 1992.

4 Standing Committee on Postgraduate Medical Education. Formal opportunities in postgraduate education for hospital doctors in opportunities in postgraduate educar
training. London: SCOPME, 1992.

5 Campling EA. Report of national confidential enquiry into perioperative deaths. London: NCEPOD, 1992 